\author{
Research article \\ urn:1sid:zoobank.org:pub:F62C0C1C-720B-4442-825F-F502AD3A9443
}

\title{
Neoclita pringlei (Scarabaeidae, Cetoniinae), a new relict genus and species from the Drakensberg Range of South Africa
}

\author{
Renzo PERISSINOTTO \\ School of Environmental Sciences, Nelson Mandela Metropolitan University, \\ PO Box 77000, Port Elizabeth 6031, South Africa, and \\ School of Life Sciences, University of KwaZulu-Natal, P Bag X54001, Durban 4001, South Africa. \\ Email: renzo.perissinotto@nmmu.ac.za
}

urn:1sid:zoobank.org:author:641CADAE-2E9B-4449-8590-8238C1265598

\begin{abstract}
A new genus is erected within the Cetoniini to describe a newly discovered species with characters shared between Heteroclita Burmeister, 1842, Ichnestoma Gory \& Percheron, 1833 and Meridioclita Krikken, 1982. Neoclita pringlei gen. et sp. nov. exhibits a simple clypeal structure without specialized armour, along with hypertrophic and hairy tarsal segments as well as a fully winged female. The new species also exhibits an aedeagal structure closest to Meridioclita, with dorsal lobes of parameres substantially narrower than the ventral ones. The species appears to be restricted to high altitudes in the southwestern peri-Drakensberg area of the Eastern Cape Province, South Africa. Similarly to other mountain relicts known from the southern African region, adults emerge only after major rainfall events during the late spring to early summer season and do not show any evidence of feeding. It appears that flying activity may be temporarily interrupted following soil desiccation, to resume promptly after the next rainfall.
\end{abstract}

Keywords. New genus, new species, Heteroclita, Ichnestoma, Meridioclita, Afrotropical region.

Perissinotto R. 2017. Neoclita pringlei (Scarabaeidae, Cetoniinae), a new relict genus and species from the Drakensberg Range of South Africa. European Journal of Taxonomy 279: 1-12. http://dx.doi.org/10.5852/ ejt.2017.279

\section{Introduction}

The southern African region, and South Africa in particular, hosts a large diversity of relictual or primitive genera of fruit chafers, many of which are endemic and often restricted to small distribution ranges. Keeping in mind that the validity of the current subtribal classification is yet to be verified with suitable phylogenetic analyses, among these are recently-described members of the Xiphoscelidina, Goliathina and Coryphocerina (Holm \& Marais 1992; Smith et al. 1998; Perissinotto et al. 2003; Holm \& Perissinotto 2004). These include the genera Protoclita Krikken, 1978, Ischnostomiella Krikken, 1978, Xiphoscelis Burmeister, 1842, Ichnestoma Gory \& Percheron, 1833, Heteroclita Burmeister, 1842, Meridioclita Krikken, 1982, Paraxeloma Péringuey, 1907 and Rhinocoeta Burmeister, 1842, for example. 
Unfortunately, this region remains largely unexplored due to inadequacy of dedicated research as well the vastness and inaccessibility of many of its parts. To compound this problem is the fact that virtually all these genera exhibit a very short period of adult activity, generally coinciding with substantial rainfall events during the warmest part of the year (i.e., austral spring and summer). They do not feed at the adult stage, having generally obsolete or atrophic mouth parts, and therefore can only support their basal metabolic demands and reproductive activities using the energy reserves accumulated during the period of larval growth. As a result, most species only live for a few days to weeks at the most, depending on their ability to undertake dormancy while soil moisture is inadequate (Holm \& Marais 1992; Perissinotto et al. 2003).

A new genus is described here on the basis of recent collections undertaken in relatively remote areas of the peri-Drakensberg region of the Eastern Cape Province, South Africa. This genus exhibits some characteristics that are typical of either Heteroclita (e.g., clypeal shape), Ichnestoma (e.g., hypertrophic tarsi) or Meridioclita (e.g., aedeagal structure) and also some unique characters (e.g., virtual lack of dorsal setation, dorsal convexity, hexagonal pronotal shape) that altogether require the erection of a new, separate taxon.

\section{Material and methods}

Specimens were collected during three separate surveys of the Matatiele Nature Reserve (6 Dec. 2008) and the mountainous area adjacent to the town of Dordrecht (12 Dec. 2013 and 31 Dec. 2015), respectively. On all occasions, specimens were either collected in flight using a standard entomological net or on the ground by hand and immediately killed with ethyl acetate vapours.

The description of morphological characters follows the terminology used by Krikken (1984) and Holm \& Marais (1992). Specimen length represents the total distance from the anterior margin of the clypeus to the apex of the pygidium, while width represents the maximum width of the elytra. Photos of specimen dorsal and ventral habitus were taken with a Nikon CoolPix S9700 digital camera with macro setting, while photos of the male genitalia were obtained using a Nikon DigitalSight DS-Fi2 camera attached to a Nikon SMZ25 dissecting microscope. In all photos, the background was removed using Microsoft Word 2010 (Picture Tools), in order to increase clarity of resolution. The Combine ZP Image Stacking Software by Alan Hadley (alan@micropics.org.uk) was used to obtain z-stacking composite images.

Repository collections are abbreviated as follows:

$\mathrm{BMPC}=$ Jonathan Ball and Andre Marais Private Collection, Cape Town, South Africa

DMPC $=$ Daniel Moore Private Collection, Oro Valley, USA

EPPC = Ernest Pringle Private Collection, Bedford, South Africa

ISAM = Iziko South African Museum, Cape Town, South Africa

RPPC = Renzo Perissinotto and Lynette Clennell Private Collection, Port Elizabeth, South Africa

TGPC $=$ Thierry Garnier Private Collection, Montpellier, France

SANC $=$ South African National Collection of Insects, Pretoria, South Africa

SRPC = Sébastien Rojkoff Private Collection, Lyon, France

TMSA = Ditsong National Museum of Natural History (formerly Transvaal Museum), Pretoria, South Africa 


\title{
Results
}

\author{
Order Coleoptera Linnaeus, 1758 \\ Family Scarabaeidae Latreille, 1802 \\ Subfamily Cetoniinae Leach, 1815 \\ Tribe Cetoniini Leach, 1815 \\ Genus Neoclita gen. nov. \\ urn:1sid:zoobank.org:act:D37A96FD-8F4D-48DD-98EA-18CAB3486551
}

\section{Type species}

Neoclita pringlei gen. et sp. nov.

\section{Diagnosis}

The most unique features of Neoclita gen. nov. are its remarkably short clypeus and its extremely narrow and reduced mesometasternal process. Also unusual are the general oval shape of the body and the rather hexagonal anteroposteriad (male) to hemicircular (female) pronotal shape, which deviates substantially from the typical trapezoidal shape of the pronota found in the closely related genera (Figs 1, 3-4).

The new genus exhibits symplesiomorphic similarities with both Heteroclita and Ichnestoma. With Heteroclita, it shares the general shape of its clypeus, although this is much shorter and not bilobate in Neoclita gen. nov. , the generally rounded elytra with weakly raised costae and a fully winged female. With Ichnestoma, Neoclita gen. nov. shares the unequivocal hypertrophy of its male tarsomeres, which are particularly elongated on the metalegs, and the presence of tomentose markings on elytra and pygidium (Figs 1, 4).

The aedeagal structure, however, does not reflect any affinity to Ichnestoma and is also poorly comparable to that of Heteroclita. It is actually much closer to that of Meridioclita, by virtue of the expansion of the ventral lobes which are about twice as large as the dorsal ones (Fig. 2). Finally, the drastically reduced setation on the dorsal body surface of Neoclita gen. nov. is an outlying character, which appears to relate this genus to some extent also to the more recent genera of the Goliathina (e.g., Hypselogenia Burmeister, 1842) and Coryphocerina (e.g., Lansbergia Ritsema, 1888).

\section{Etymology}

The name of the new genus arises from the latest discovery of another taxon in the "clita" grouping.

\section{Key characters}

1) Body moderately deplanate in male, with lateral margins smooth to rounded; general shape dorsally more convex and laterally more rounded in female.

2) Clypeus tranverse and unarmed in both sexes, smoothly rounded and concave, upturned but not bilobate; mouth parts atrophic.

3) Antennal clubs approximately twice as large in male as in female, but not hypertrophic.

4) Pronotum hexagonal to semicircular in shape, exhibiting few scattered and short setae at margins, but dense, fine round sculpture throughout; anterior angles very rounded, anterior margin remarkably wide and atuberculate; prescutellar arch poorly developed.

5) Scutellum triangular and sharply acuminated at apex, without lateral grooves.

6) Elytra with very slight posthumeral emargination; costae poorly raised in male and hardly discernible in female; female with fully developed wings.

7) Pygidium simple, without indentations and exhibiting scattered, short setae. 
8) All tarsal segments extremely elongated in male, but of normal length in female.

9) Protibia tridentate, with extreme reduction of proximal tooth in male.

10) Meso- and metatibia with no or poorly developed outer carina and spines in male, but one prominent spine present on each in female.

11) Metatibial spurs moderately long and robust in male, but slender and short in female (no specialized fossorial adaptation).

12) Ventral surface with widespread setae, particularly dense on anterior prosternal margin, mentum and legs.

13) Mesometasternal process narrow, extremely reduced and smoothly rounded.

14) Aedeagus with dorsal parameral lobes narrower than ventral and exhibiting very scattered, short setae dorso-apically.

Neoclita pringlei gen. et sp. nov. urn:1sid:zoobank.org:act:88D0989D-50F5-4265-8C3A-2C1DBC4151EE

Figs $1-7$

\section{Etymology}

The species is named after the renowned South African lepidopterologist Ernest Pringle, who first collected the new species in the Matatiele Nature Reserve and promptly brought it to my attention.

\section{Type material}

\section{Holotype}

SOUTH AFRICA: Ô, KwaZulu-Natal, Matatiele 6 Dec. 2008, R. Perissinotto and L. Clennell leg. (TMSA).

\section{Paratypes}

SOUTH AFRICA: $23 \hat{\jmath} \widehat{\partial}, 2$ 우, same data as holotype (TMSA, SANC, ISAM, BMPC, PCPC, TGPC, DMPC, CDPC, SRPC); $13 \hat{\partial} \widehat{\partial}$, same locality as holotype, but 29 Nov. 2008, E.L. Pringle leg. (EPPC, PCPC); $18 \hat{\jmath} \widehat{\jmath}, 9$ 우, E Cape Prov., Dordrecht Mountain, 1740 m, 12 Dec. 2013, 31 ${ }^{\circ} 22^{\prime} 28.70^{\prime \prime}$ S, $27^{\circ} 03^{\prime} 15.80^{\prime \prime}$ E, A.P. Marais and J.B. Ball leg. (BMPC, PCPC); 1 ${ }^{\lambda}$, same locality as holotype, but 31 Dec. 2015, E.L. Pringle leg. (EPPC).

\section{Description of holotype (Figs 1-2)}

SizE. Length 16.3; width $9.4 \mathrm{~mm}$.

BoDy. Black to dark brown, with tomentum on scutellum, elytra and pygidium (Figs 1A, 4); shape remarkably oval, with convexity particularly enhanced on apical parts of elytra (Fig 1A).

HEAD. Black, with few scattered setae on margins of clypeus and frons, completely covered in dense, fine round punctures except on clypeal ridges and supra-ocular tubercle; clypeus extremely short and sharply upturned at anterior margin but less so at lateral margins, not bilobate; frons and vertex exhibiting smooth elevation at middle forming a mild convexity above anteriorly sloping disc (Fig. 1A).

Pronotum. Antero-hexagonal with angles smoothly rounded; anterior margin without tubercle or ridge, but exhibiting broad, sharply downturned ocular lobes which extend beyond eyes; black to brown, shiny with dense, fine round punctures evenly distributed throughout surface, except at lateral and posterior margins; lateral margins carinate and bearing short, scattered setae; posterior margin shiny and smooth, slightly sinuate anteriad of scutellum to form poorly developed pre-scutellar arch (Fig. 1A). 
Scutellum. Black to dark brown; with few scattered round punctures exhibiting seta at centre; perfectly triangular, with sharp apex; without lateral groove, but with oblong tomentose area on each side reaching neither base nor apex (Fig 1A).

ELYTRON. Exhibiting poorly raised sutural, discal and lateral costae; uneven costae 3, 5 and 7 converging at apical callus; colour varying from light to dark brown, with even numbered interstriae and lateral declivity exhibiting tomentose lines and spots; humeral callus pronounced, but apical callus virtually obsolete; apical third extremely convex, resulting in oval shape; sparse fine, round punctures with short yellow setae at centre occurring only on lateral and apical declivities (Fig. 1A).
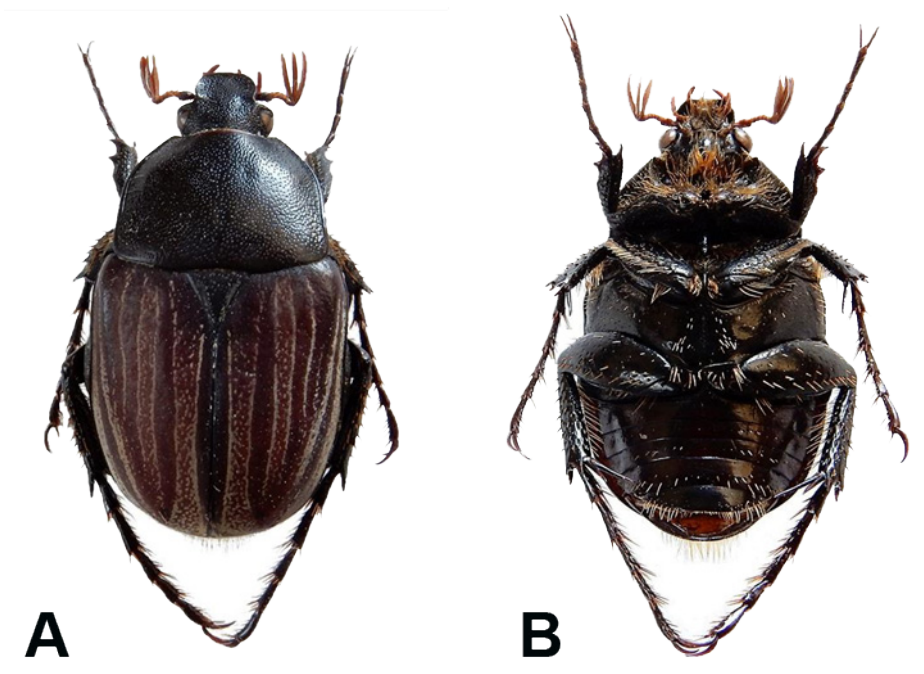

Fig. 1. Neoclita pringlei gen. et sp. nov., holotype, $\widehat{\jmath}$, total length $=16.3 \mathrm{~mm}$. A. Habitus, dorsal view. B. Habitus, ventral view. (South Africa, Eastern Cape Province, Matatiele Nature Reserve, 6 Dec. 2008, R. Perissinotto and L. Clennell leg.)

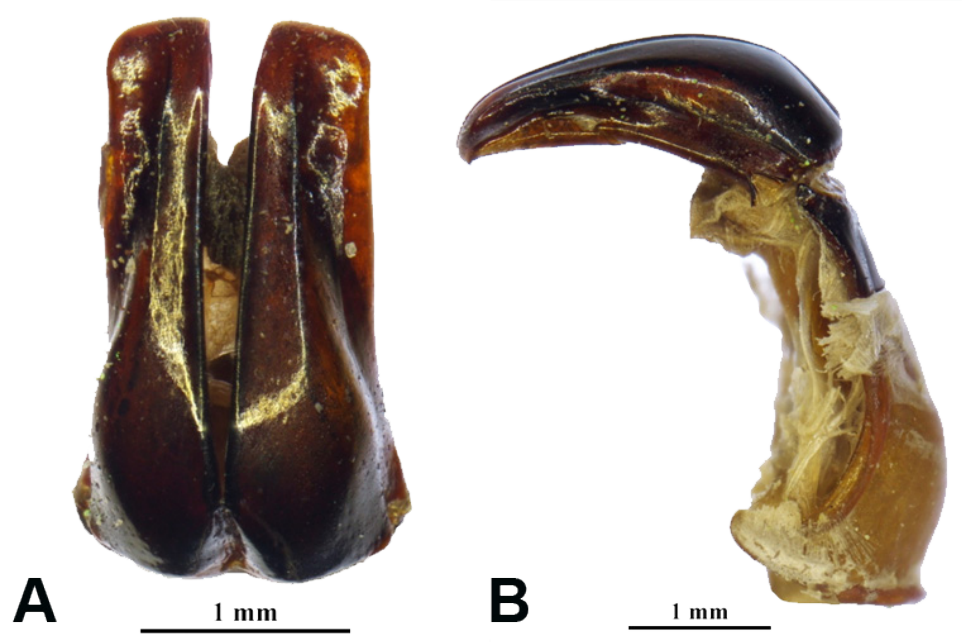

Fig. 2. Neoclita pringlei gen. et sp. nov., holotype, ふ̂. A. Aedeagus, dorsal view. B. Aedeagus, lateral view. (South Africa, Eastern Cape Province, Matatiele Nature Reserve, 6 Dec. 2008, R. Perissinotto and L. Clennell leg.) 

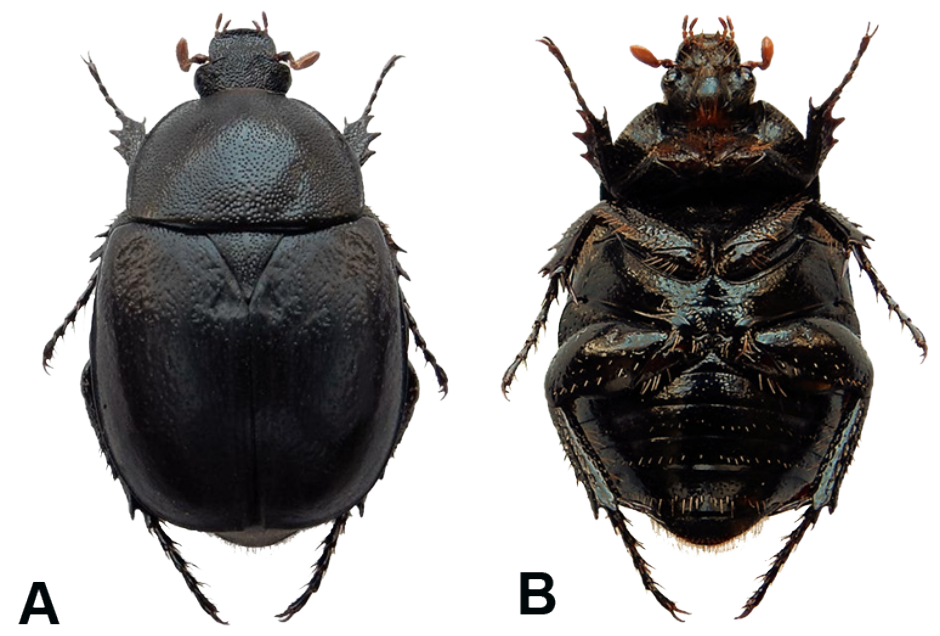

Fig. 3. Neoclita pringlei gen. et sp. nov., paratype,, , total length $=16.8 \mathrm{~mm}$. A. Habitus, dorsal view. B. Habitus, ventral view. (South Africa, Eastern Cape Province, Matatiele Nature Reserve, 6 Dec. 2008, R. Perissinotto and L. Clennell leg.)

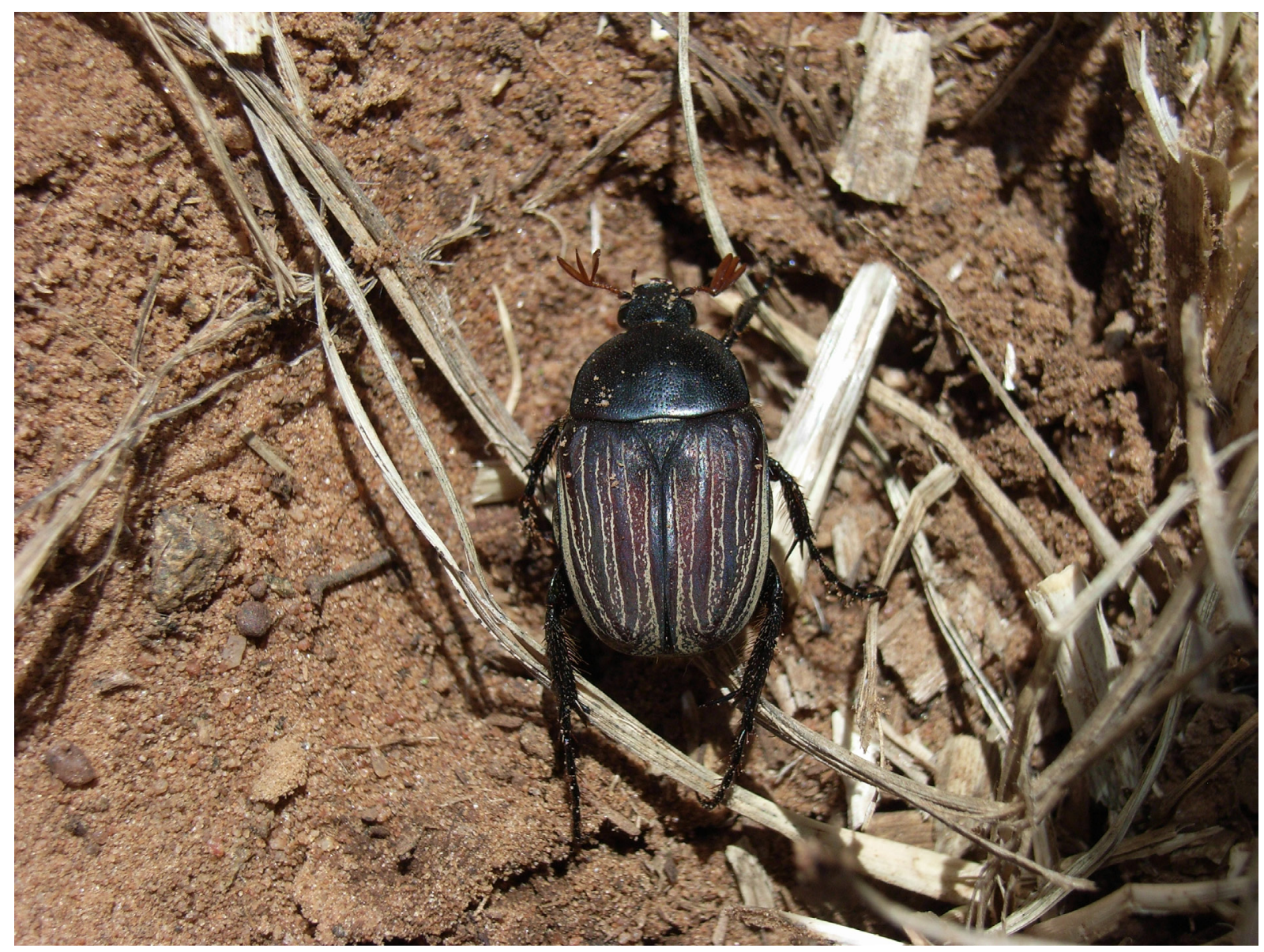

Fig. 4. Neoclita pringlei gen. et sp. nov., Ô, specimen in its natural habitat (photo: Lynette Clennell, Matatiele, 6 Dec. 2018). 
PyGiDIUM. Dark brown but completely covered in whitish tomentum, except at apex; scattered small round punctures throughout, with short seta at centre of each puncture; without any prominent indentation or protrusion.

Appendages. Antennal clubs reddish brown, of normal length, of approximately the same length of pedicel and flagellum combined; pedicel dark brown to black, flagellum reddish brown, both with scattered but long, erect yellow-brown setae; legs strongly built in male, femora and tibias enlarged (cf. Meridioclita); protibia slender, with yellow-brown setae short and scattered on outer margin, becoming longer and denser on inner margin, tridentate with proximal tooth poorly developed to obsolete; mesoand metatibia with longer yellow-brown setae, again longer and denser on inner than outer margin, with no outer carina and relatively poorly developed spines; metatibial spurs long, slender and sharply pointed; profemur and mesofemur covered with long and dense yellow-brown setae, becoming few and short on metafemur; tarsomeres of all legs elongate and hypertrophic, with yellow-brown setae at joints and on inner margin (Fig. 1A).

UNDERSIDE. Shiny black to dark brown; small, round punctures throughout surface but very scattered and mostly bearing setae at centre; yellow-brown, long setae throughout anterior surface, becoming short and scattered on metasternum and abdominal sternites; mesometasternal lobe extremely narrow, reduced and smoothly rounded; abdominal sternites with visible concavity at centre and without tomentose markings (Fig. 1B).

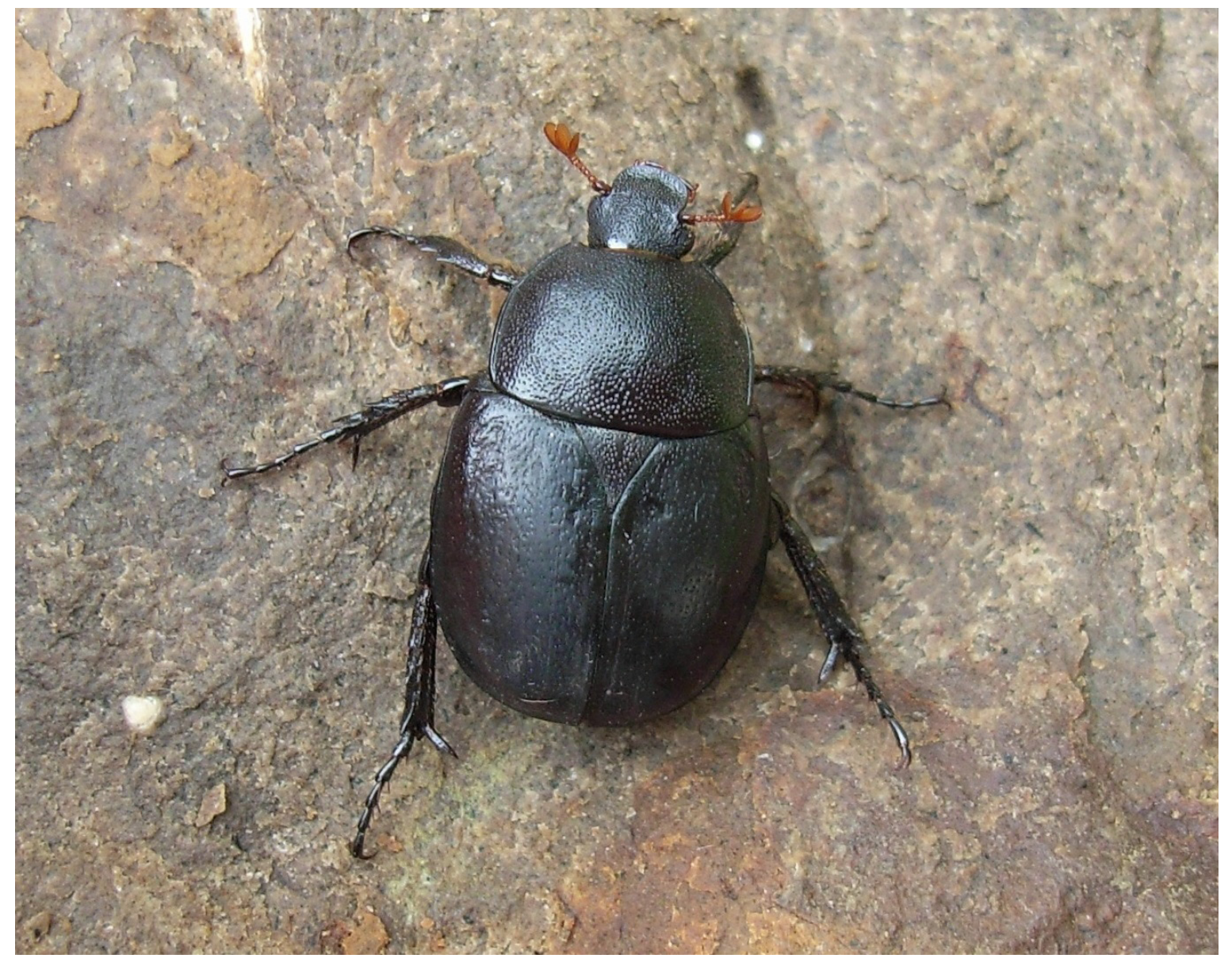

Fig. 5. Neoclita pringlei gen. et sp. nov., + , specimen in its natural habitat (photo: Lynette Clennell, Matatiele, 6 Dec. 2018). 
Aedeagus. Parameres relatively short and compact (Fig. 2), with dorsal lobes narrower than ventral lobes; dorsal lobes with upper margin concave across full length; apices blunt and broadly rounded in dorsal view, exhibiting short scattered setae throughout dorso-frontal surface (Fig. 2).

\section{Description of female}

The female differs markedly from the male, exhibiting the typical black and globose body of the genera Heteroclita, Ichnestoma and Meridioclita (Figs 3, 5). It possesses fully developed wings. Its antennal clubs are approximately half of the length of those of the male and the pronotum is virtually hemicirclic, rather than hexagonal. The protibia is markedly tridentate and both meso- and metatibia exhibit a sharp median tooth on external margin, which on the other hand is poorly developed in the male. Tarsal segments are of normal length, lacking the typical hypertrophy of males. As in all related genera, the female also exhibits a slight convexity at the middle of its abdominal tergites (Fig. 3B).

\section{Type series variability}

Size range: ${ }^{\lambda}$ : length $14.6-17.3 \mathrm{~mm}$, width $7.9-8.8 \mathrm{~mm}(\mathrm{n}=18)$; + : length $15.2-16.8 \mathrm{~mm}$, width $8.7-$ $9.1 \mathrm{~mm}(\mathrm{n}=6)$.

There is very little colour variability among male specimens in the type series, while females are all consistently black. Males vary slightly in the extent of the tomentose stripes on the elytral surface. The oblong tomentose area on each side of the male scutellum may reach the base in some specimens. The

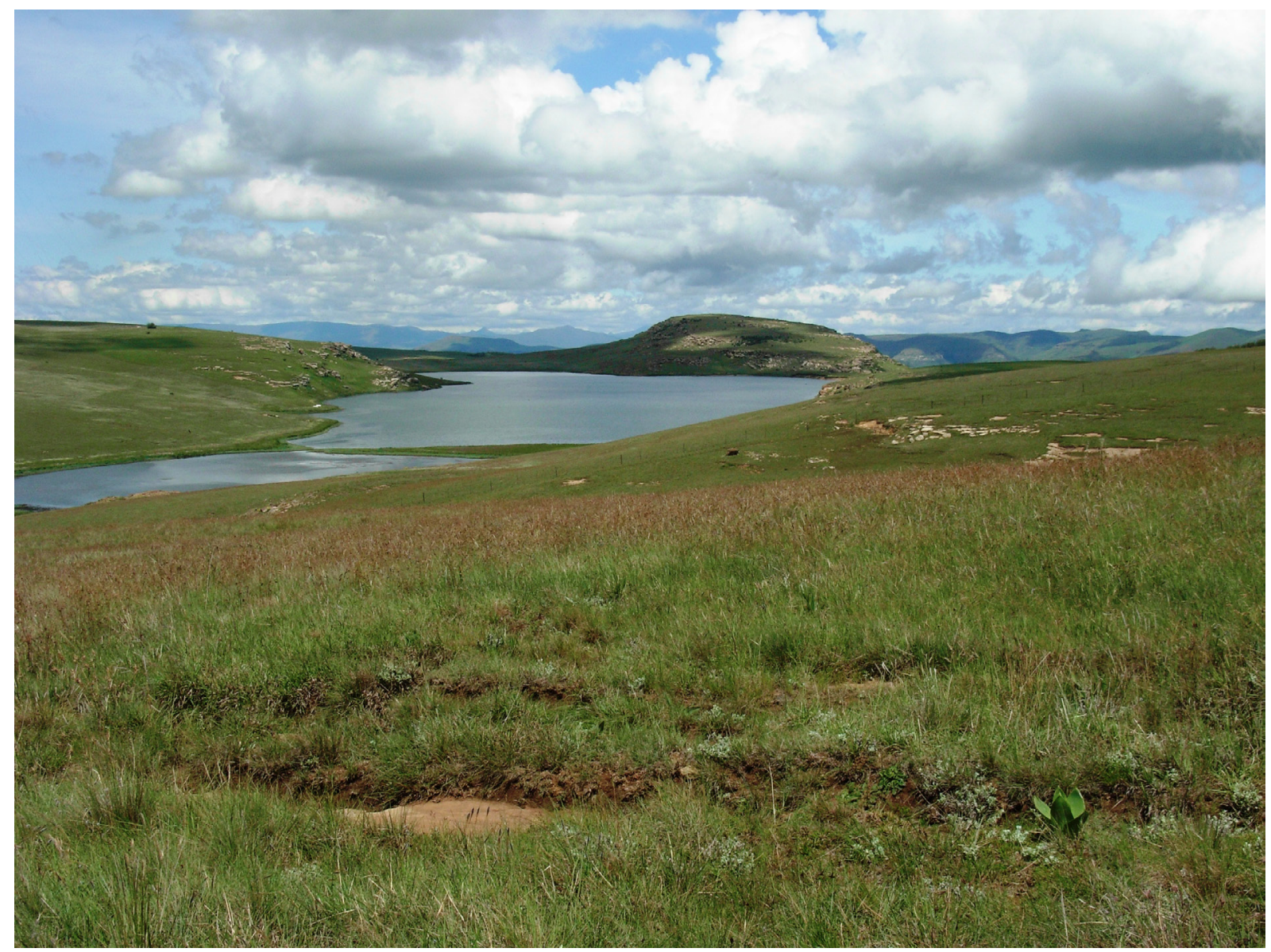

Fig. 6. Matatiele Nature Reserve, showing the mountain summit with the typical habitat of Neoclita pringlei gen. et sp. nov. (photo: Lynette Clennell, Matatiele, 6 Dec. 2008). 
pygidial background colour can vary from dark brown to reddish brown in the male. Most specimens also exhibit rapid discolouration after death, creating an apparent dark brown uniform colouration. This is solely due to impregnation of the surface chitin layer with oily substances, which can be readily removed by keeping the specimen immersed in acetone (or similar organic detergents) for a few days / weeks. Finally, the extent of dorsal pilosity in males varies from virtual absence to scattered coverage throughout much of the surface. Dorsal setae are generally extremely short, except on frons where they may be longer in fresh specimens.

\section{Discussion}

Neoclita pringlei gen. et sp. nov. represents the latest discovery in the already diverse group of relictual cetoniine taxa that occurs in southern Africa. Neoclita gen. nov. shares characters with at least three other genera from the region, which are regarded as primitive, with ancestral features (Krikken 1984; Holm \& Marais 1992). These are Heteroclita, Ichnestoma and Meridioclita. With the first, Neoclita gen. nov. shares the shape of the clypeus and rounded elytra with weakly raised costae. With Ichnestoma, Neoclita gen. nov. shares the hypertrophy of male tarsomeres and the tomentum on elytra and pygidium, while with Meridioclita it shares mainly the aedeagal structure. With both Meridioclita and Heteroclita, Neoclita gen. nov. also shares a fully winged female. The drastically reduced dorsal setation is the only character which appears to relate this genus to the more recent genera of the Goliathina and Coryphocerina.

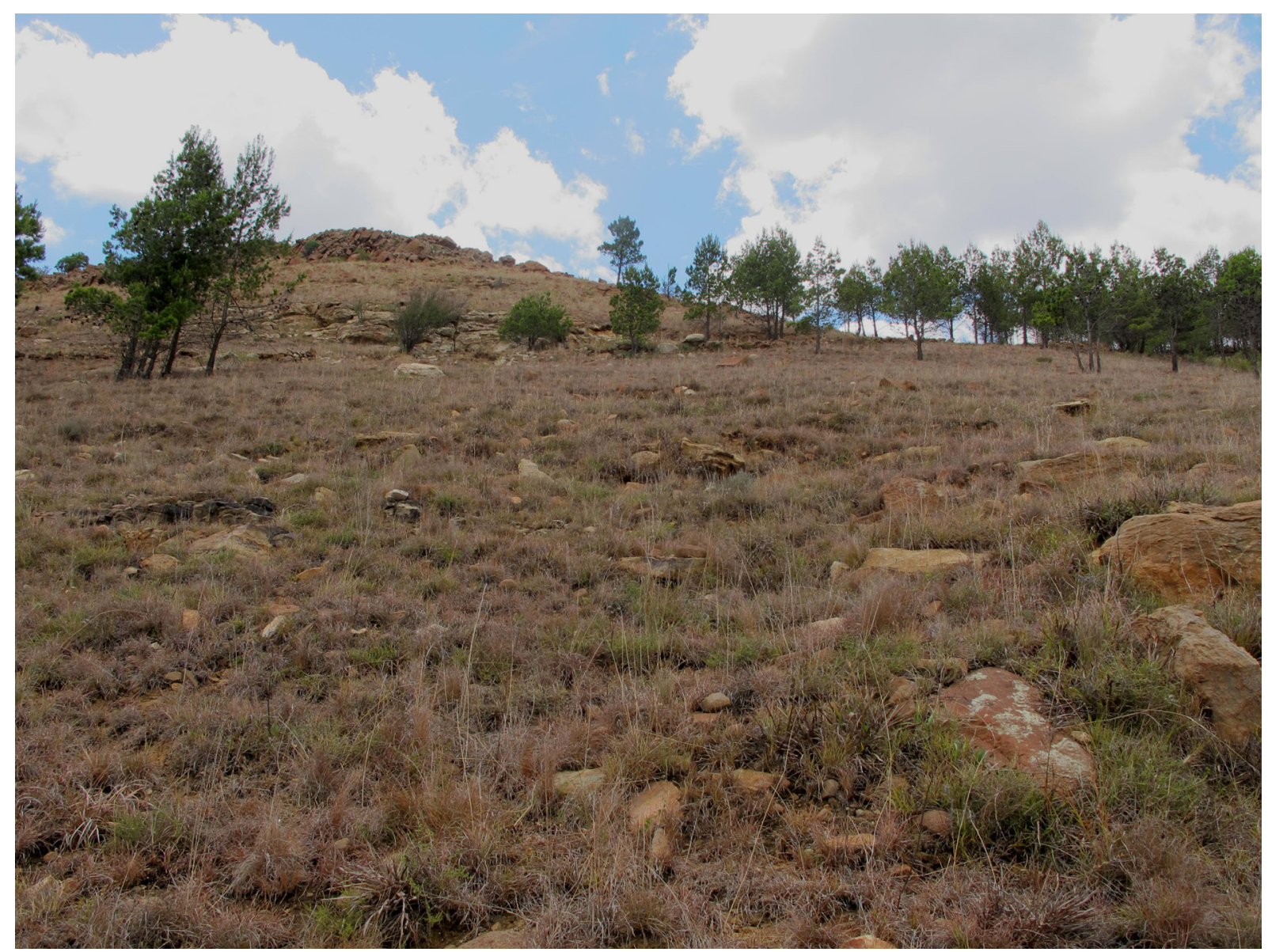

Fig. 7. Dordrecht Mountain, where a second population of Neoclita pringlei gen. et sp. nov. was first recorded in Dec. 2013 (photo: Lynette Clennell, Dordrecht, 31 Dec. 2015). 
Holm \& Marais (1992) regarded Meridioclita as the "most primitive known African cetoniine". They also suggested that Heteroclita most probably derived from near Meridioclita. It has recently been shown that both genera have fully winged females (Holm \& Perissinotto 2011; pers. obs.). Thus, the apterous/brachypterous condition of female Cetoniini, such as that of most species currently included in the genus Ichnestoma, may not be an expression of their primitive state, but rather a convergent strategy adopted by a variety of species that occur in arid and/or montane habitats (Holm \& Marais 1992; Holm \& Perissinotto 2011). A proper phylogenetic study, inclusive of molecular data, is thus needed at this stage in order to resolve with reasonable confidence the position of all these relictual taxa.

Neoclita pringlei gen. et sp. nov. appears to be restricted to elevations close to the summit of the Great Escarpment on the south-eastern side of the Drakensberg mountain range, in the Eastern Cape and possibly also in KwaZulu-Natal, as the locality of Matatiele is right at the border between the two provinces and, in fact, used to be part of KwaZulu-Natal until 2005. The area receives an average rainfall of $780 \mathrm{~mm}$ per year, within a range of $500-1120 \mathrm{~mm}$, increasing from west to east (Mucina \& Rutherford 2006). Most rain events occur in the austral summer (December-February), while winters tend to be very dry. The mean annual temperature of $13^{\circ} \mathrm{C}$ is indicative of a typically montane and cooltemperate climate, with frost and snow falls regularly occurring in winter (Mucina \& Rutherford 2006).

The vegetation type at high altitude above Dordrecht and Matatiele is Southern Drakensberg Highland Grassland (Unit Gd 4 of Mucina \& Rutherford 2006). This is characterized by dense tussock grassland on steep slopes, with dwarf shrubland prevailing on exposed rocky surfaces (Figs 6-7). Several endemic taxa of biogeographic importance are found amongst the graminoids, the herbs, the geophytes and the low shrubs (Mucina \& Rutherford 2006). From a conservation point of view, this grassland type is widely regarded as least threatened, because of the relatively high proportion already protected at statutory level (e.g., uKhahlamba Drakensberg World Heritage Site, Malekgonyane Wildlife Reserve) and the very small area currently transformed for agriculture, with low erosion impact. Alien invasive plant species are, however, encroaching in large sections of the two localities where N. pringlei gen. et sp. nov. is currently known to occur.

All specimens of $N$. pringlei gen. et sp. nov. recorded so far have been collected at high altitudes, between 1724 and $1805 \mathrm{~m}$. Males fly fast, about $80-150 \mathrm{~cm}$ above the ground, most often in areas with dense and tall grass, while females remains generally hidden underground while laying eggs. They surface occasionally, to crawl to the next egg-laying spot, which is generally selected among the thickest grass tufts, probably in order to combine maximum food supply for the larvae with adequate protection from desiccation during hot and dry periods. As observed previously with other primitive/relictual members of the Xiphoscelidina, Goliathina and Coryphocerina, adults emerge from their underground cocoons only after major rainfall events in the late spring or summer (Perissinotto et al. 1999; Holm \& Perissinotto 2004). A peak in adult activity is observed immediately after the rain, and especially when temperatures rise above the critical level of $25^{\circ} \mathrm{C}$. Following the desiccation of the soil, however, adults have been seen disappearing again underground to reappear at the surface only after a new rainfall event, a week or two later.

A similar behavioural pattern has recently been observed in Heteroclita haworth (Gory \& Percheron, 1833 ) in the Winterberg mountains, further to the west (E.L. Pringle, pers. comm.). Here, the species in question appears to undergo a regular alternation of periods of activity and dormancy, in synchrony with moisture saturation in the upper layer of soil and its desiccation, respectively. This would allow adults to optimise the cost-effectiveness of their efforts while moving in and out of the soil for reproductive purposes. In this context, it is important to recall that neither female nor male adults have ever been observed feeding on flowers or fruits, and indeed their mouthparts are atrophic and probably nonfunctional. 
Neoclita pringlei gen. et sp. nov. exhibts a fully winged female, as that of Heteroclita and Meridioclita, but its ability to fly has not yet been confirmed. Holm \& Marais (1992: 47) erroneously referred to "the apterous females of Heteroclita", but actually both species occurring in southern Africa and reported in their work have fully developed wings, similar in length and surface area to those of their male counterparts. It is possible that these females and those of $N$. pringlei gen. et sp. nov. fly only after they have laid most of their eggs within crawling distance of their place of emergence. That would make them substantially lighter in weight and able to take off. This behaviour has been observed in at least two species currently included in the genus Ichnestoma, but probably in need of revision and re-allocation, namely I. patera (Gory \& Percheron, 1833) and I. perstriata Holm, 1992 (pers. obs.).

\section{Acknowledgements}

The Chief Directorate: Environmental Affairs of the Eastern Cape Department of Economic Affairs, Environmental Affairs and Tourism and the management of the Matatiele Nature Reserve are gratefully acknowledged for providing logistical assistance and permits for this study. Ernest Pringle, Jonathan Ball and Andre Marais are thanked for providing valuable material and information towards this study. Thanks also to Lynette Clennell and Liza Rishworth for taking the photos included in the manuscript. This work was supported by productivity grants awarded by the University of KwaZulu-Natal (Durban) and the Nelson Mandela Metropolitan University (Port Elizabeth), South Africa.

\section{References}

Holm E. \& Marais E. 1992. Fruit Chafers of Southern Africa (Scarabaeidae: Cetoniini). Ekogilde, Hartbeespoort, South Africa.

Holm E. \& Perissinotto R. 2004. New and lesser known species of African fruit chafers (Coleoptera Scarabaeidae Cetoniinae). Tropical Zoology 17: 73-95. http://dx.doi.org/10.1080/03946975.2004.105 $\underline{31200}$

Holm E. \& Perissinotto R. 2011. New descriptions and revisions of southern African Cetoniinae (Coleoptera: Scarabaeidae). I. African Entomology 19 (1): 88-95.

Krikken J. 1984. A new key to the suprageneric taxa in the beetle family Cetoniidae, with annotated lists of the known genera. Zoologische Verhandelingen 210: 3-75.

Mucina L. \& Rutherford M.C. 2006. The Vegetation of South Africa, Lesotho and Swaziland. Strelitzia 19, South African National Biodiversity Institute, Pretoria.

Perissinotto R., Smith T.J. \& Stobbia P. 1999. Description of adult and larva of Ichnestoma pringlei n. sp. (Coleoptera Scarabaeidae Cetoniinae), with notes on its biology and ecology. Tropical Zoology 12: 219-229. http://dx.doi.org/10.1080/03946975.1999.10539390

Perissinotto R., Villet M.H. \& Stobbia P. 2003. Revision of the genus Xiphoscelis Burmeister 1842 (Coleoptera Scarabaeidae Cetoniinae), with description of two new species and notes on its phylogeny Tropical Zoology 16: 63-82. http://dx.doi.org/10.1080/03946975.2003.10531184

Smith T.J., Perissinotto R. \& Villet M.H. 1998. The larva of Rhinocoeta sanguinipes (Gory \& Percheron 1833) (Coleoptera Scarabaeidae): description and phylogenetic inferences. Tropical Zoology 11: 225234. http://dx.doi.org/10.1080/03946975.1998.10539365

Manuscript received: 15 April 2016

Manuscript accepted: 8 June 2016

Published on: 16 February 2017 
Topic editor: Gavin Broad

Desk editor: Kristiaan Hoedemakers

Printed versions of all papers are also deposited in the libraries of the institutes that are members of the EJT consortium: Muséum national d'Histoire naturelle, Paris, France; Botanic Garden Meise, Belgium; Royal Museum for Central Africa, Tervuren, Belgium; Natural History Museum, London, United Kingdom; Royal Belgian Institute of Natural Sciences, Brussels, Belgium; Natural History Museum of Denmark, Copenhagen, Denmark; Naturalis Biodiversity Center, Leiden, the Netherlands. 